\title{
Extracting sea level residual in tidally dominated estuarine environments.
}

\author{
Submission for Ocean Dynamics
}

\section{Jennifer M. Brown ${ }^{\text {a,* }}$, Rodolfo Bolaños a, Michael J. Howarth ${ }^{\text {a }}$, Alejandro J. Souza $^{\text {a }}$}

a National Oceanography Centre, Joseph Proudman Building, 6 Brownlow Street, Liverpool, L3 5DA, UK.

* Corresponding author Phone: +44 (0) 151795 4971, Fax: +44 (0) 151795 4801, Email: jebro@noc.ac.uk (J.M. Brown)

\begin{abstract}
Sea level comprises a mean level, tidal elevation and a residual elevation. Knowledge of what causes maximum water levels is often key in coastal management. However, different methods to extract deviations in water level (residuals) from modelled and observed elevation can give different results. The Dee Estuary, northwest England, is a macrotidal estuary that undergoes periodic stratification. It is used here to demonstrate methods to extract the residual water level in response to the following interactive processes: tidal, river induced stratification and flow, meteorological and waves. Using modelling techniques the interaction and contribution of different physical processes are investigated. Classical harmonic tidal analysis, model simulations and filtering techniques have been used to "de-tide" the total elevation for short-term ( $\sim$ month long) records. Each technique gives a different result highlighting the need to select the
\end{abstract}


correct method for a required study. Analysis of the residual components demonstrates that all processes inducing residuals interact with the tide generating a semi-diurnal residual component. It is suggested that modelling methods enable the full effect of tidal interaction to remain in the residual, while harmonic tidal analysis (partly) modify and filtering methods (fully) remove this component of the residual. The analysis methods presented and their influences on the resultant residual are applicable to other study sites. However, when applied specifically to the mouth of the Dee Estuary, the external surge is found to be the main contributor to the total residual, while local wind and stratification effects are of secondary importance.

Keywords: Dee Estuary; tide-surge-stratification; POLCOMS-GOTM-WAM; flood management; residual water level.

\section{Introduction}

The Dee Estuary lies on the Welsh-English border in northwest England (Fig. 1). It experiences semi-diurnal tides with a maximum range of $\sim 10 \mathrm{~m}$, making it a macrotidal estuary with a vast expanse of drying banks that form a network of tidal channels. At the estuary mouth diurnal and higher harmonic tidal constituents are small, the $\mathrm{O}_{1}, \mathrm{~K}_{1}$ and $\mathrm{M}_{4}$ at Hilbre Island contribute approximately $0.11 \mathrm{~m}, 0.11 \mathrm{~m}$ and $0.20 \mathrm{~m}$ respectively. Although river flow is weak, with an annual average of $31 \mathrm{~m}^{3} / \mathrm{s}$ in 2008 , typical estuarine stratification occurs at low tide due to the relative importance of the river during low (constrained) water levels and tidal straining (Bolaños et al., 2011). The Dee has two contrasting coastlines, with industry in the south extending north along the west coast and a more natural east coast. Past manmade intervention within the inner estuary system, e.g. river canalisation in the upper estuary, has led to siltation making the upper estuary unnavigable from the middle of the 15th century (Pye, 1996). With the threat of increasing future sea levels (Jevrejeva et al., 2008) knowledge of water levels during storm 
events is required to defend the existing infrastructure and manage morphological storm impact along the natural coastal stretches. For engineering, knowledge of the total water level is important. The total level is made up of a mean sea level, the tides and a residual component. The residual is a combination of processes influencing the water level, such as: storm surge, atmospheric forcing and river input. In macrotidal regions the tides dominate $(>90 \%$ for Liverpool Bay) the variance and interact with the residual, making it difficult to separate the tide and residual for short-term $(\sim$ month long) records. An accurate residual is therefore required in combination with the predicted tide to obtain a good understanding of the total elevation. The modelled residual elevation extracted in this study includes interactive processes between tides, meteorology, waves and river, and could thus be used to statistically determine extreme sea levels, using techniques such as those described by Goring et al. (2011). During storms the surge level at coastal locations is normally defined as the residual elevation, i.e., the water level in addition to the predicted tidal elevation (de Vries et al., 1995). Along the coast this increase in water level is assumed to be due to wind and atmospheric pressure, and in some cases wave setup. However, within an estuary the residual water level is also influenced by the river flow, Coriolis, density-induced circulation and constrained wind-induced or wave-induced circulation. These processes have been well modelled for the Dee (see Bolaños et al., Submitted), enabling confident assessment of their influence on the residual level. The elevation residual can also be strongly affected by the nonlinear interactions between these physical processes and the tide e.g. the propagation speed of the tide can be influenced by depth changes due to the surge and vice versa. In consequence, all residuals obtained by any method from records at sampled intervals, will contain energy at the tidal frequencies in response to a process induced phase shift of the tide as it propagates in shallow water. 
In macrotidal estuaries the tide has a very strong modulating influence on the other physical processes, not only due to fast currents ( $\sim 1 \mathrm{~m} / \mathrm{s}$ during spring tide in the Dee), but also due to the wetting and drying of banks, which modify the bathymetric cross-sectional profile of the estuary. This makes it difficult to use classical harmonic tidal analysis to determine the storm-induced residual, i.e. total level minus predicted tidal level, since the tidal interaction with other physical processes can leave a strong tidal signal in the residual, which may be partly removed by the harmonic tidal analysis. Alternative modelling methods, i.e. modelled total water level minus modelled tide, are therefore used to obtain the residual elevation including all interactive effects. Great care must be taken to simulate the tide alone in a nested modelling system to ensure the tide alone simulation at the highest resolution is the same as that used in the fully forced simulation. In this study we use "model" to refer to the tidal or total outputs from the modelling system and "predicted" to refer to the tide predicted from constituents obtained from long-term (many years) tidal harmonic analysis of observation. Using the modelled tide and not the predicted tide in the modelling method prevents artificial residual being introduced due to limitation (the number of modelled tidal constituents) in the modelled tide. The residuals obtained by both harmonic and modelling methods close to the estuary mouth are compared to highlight the differences. However, for validation, consistent methods must be used. For this purpose, the residual water level was obtained by harmonic tidal analysis, applied to both the modelled and observed total water level. This removes any coherent variation with a tidal frequency, consequently removing some of the residual elevation due to tidal interaction with the processes considered. The degree to which a harmonic analysis combines the astronomic tide and residual energy depends on the length of the record analysed, i.e., a day month or year. A filtering method was then used to remove all short period $(<30 \mathrm{hrs})$ oscillation to enable further validation and assessment of the residual elevation without influence from tidal interaction. Following validation, simulations with different combinations of physical processes are used to 
determine the influence of each process on the sea surface level and to understand how they interact with the tide.

The residual water level is studied at two locations (Bolaños and Souza, 2010) near the mouth of the Dee Estuary over a 25 day period (06:00 $14^{\text {th }}$ February $-12: 009^{\text {th }}$ March 2008$)$, when an extreme offshore storm event occurred $\left(29^{\text {th }}\right.$ February 2008). River flow was small during this study period, with discharge of up to $\sim 50 \mathrm{~m}^{3} / \mathrm{s}$. Freshwater influence was greater in the Hilbre channel than the Welsh channel (Fig. 1), creating a clearer 2-layer circulation system that interacts with the tide (Bolaños et al., 2011). The following results investigate the temporal variations in water level, due to several processes and their interaction with the tide, and the differences between the residual induced in the estuarine channels. 


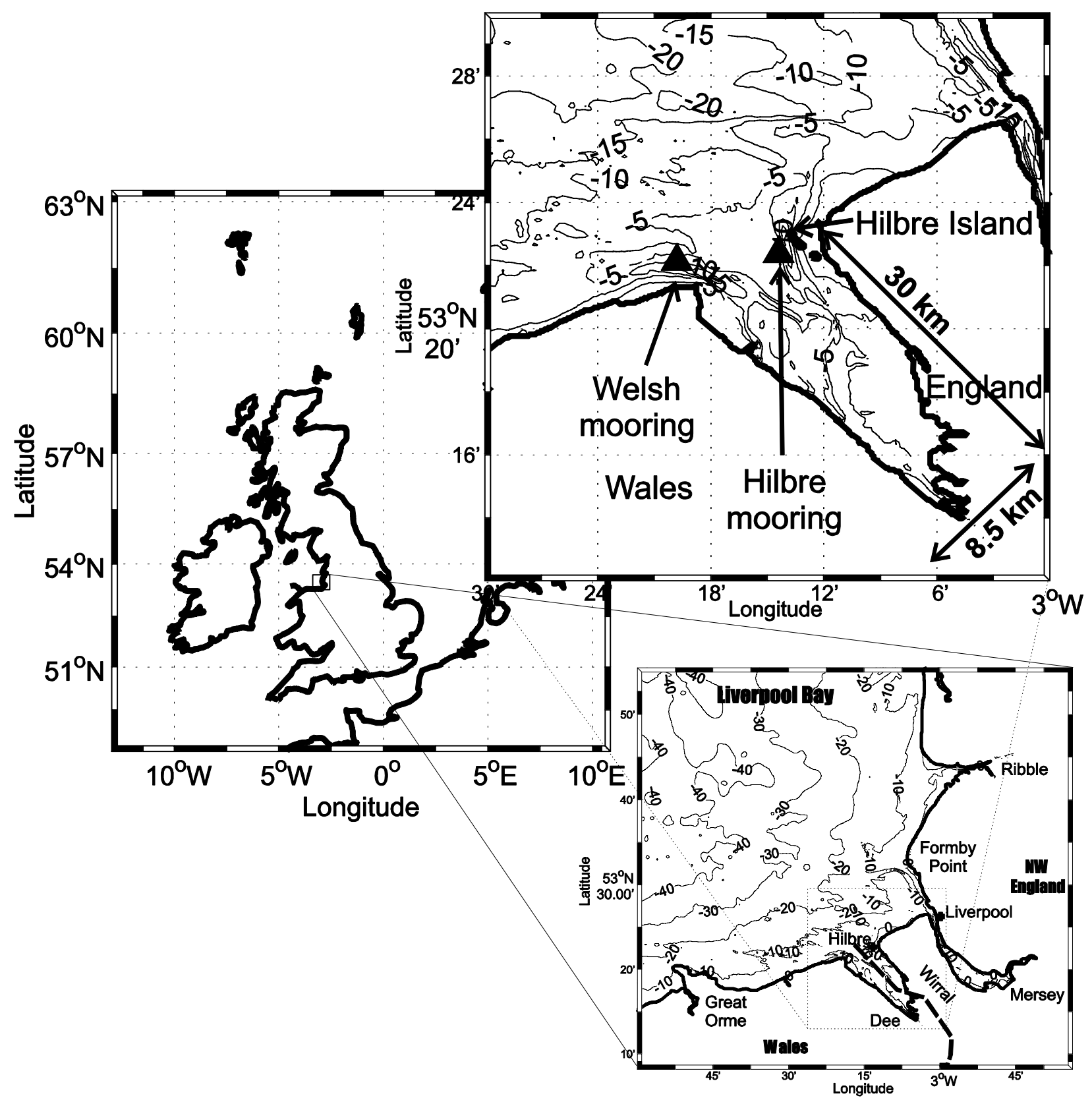

Fig. 1 The Dee Estuary, situated in Liverpool Bay northwest England, with the mooring locations (Triangles) in the main tidal channels close to the estuary mouth. The bottom panel shows the local nested model domain and the boundaries where the external forcing is imposed.

2. The modelling system and observation

The Proudman Oceanography Laboratory Coastal Ocean Modelling System (POLCOMS) coupled to the General Ocean Turbulence model (GOTM) was used to simulate tide-surge conditions within the Dee Estuary. For full details of the 3D baroclinic-barotropic POLCOMS 
model and GOTM model the reader is referred to Holt and James (2001) and Umlauf and Burchard (2005) respectively. This modelling system includes wetting and drying and also has the option to be coupled, with a 2-way exchange of information, to the WAve Model (WAM, Komen et al., 1994), modified for coastal applications (see Monbaliu et al., 2000). This enables wave enhanced bottom friction and surface stress to be included within this simulation along with wave setup, which was considered here by using a 2D approach (as in Mastenbroek et al., 1993). The local $180 \mathrm{~m}$ resolution Liverpool Bay circulation and wave model was forced with operational atmospheric conditions from the UK Met Office, while the offshore model boundary was forced by larger scale models (with $1.8 \mathrm{~km}$ resolution) so waves and surge generated over fetches towards the eastern Irish Sea were included. The model set up for this study is described by Bolaños et al. (2011) and has previously been shown to give good multi-year tide-surge hindcasts across the eastern Irish Sea (Brown et al., 2010). The coarse (operational) model has more tidal constituents available than the medium and high resolution (POLCOMS) models, therefore the coarse total tide-surge conditions were used as sequential boundary forcing in the nested modelling system. To prevent the availability of tidal constituents causing discrepancy in the modelled tides, a nested tide only simulation was also performed to accurately remove the tide from the total elevation, leaving no tidal energy in the residual. If more constituents were available, an alternative method would be to force the nested boundaries by the residual rather than total conditions, which can then be added to the nested modelled tide. This would ensure the same tidal constituents are used in the total and tidal simulations at the highest resolution.

Observations collected from pressure sensors during a study of the Dee Estuary are used to obtain the residual water elevations (Fig. 1). For instrument and deployment details see Bolaños and Souza (2010). The data provides information on the total sea surface elevation. Model time series data are extracted at these two locations to compare with the observation before it is used 
to determine the key processes driving changes in surface elevation within this macrotidal estuary, which experiences periodic stratification.

\section{Residual analysis approaches}

The tides present two complications to the study of non-tidal processes in north-west European shelf seas. Firstly the semi-diurnal tides are dominant - the variance attributed to the tides in elevation or current measurements usually exceeds $90 \%$ of the total variance and can exceed 99\%. Secondly since the time scales for residuals, for instance in response to storms ranging from hourly to one or two days, overlap with diurnal, semi-diurnal and higher harmonic tidal periodicities, the distinction between tidal and non-tidal can become blurred. Two approaches have been taken to estimating residuals - firstly calculating the tides and subtracting them from the observations and secondly low-pass filtering (Emery and Thomson, 2001).

To separate the tidal from the non-tidal component within either the modelled or observed total water elevations the classical harmonic tidal analysis method has initially been used, for example Amin (1982). In this approach the tidal forcing is represented as a set of sinusoids at specific tidal frequencies (Godin, 1972; Pugh, 1987). The longer the record, the more sinusoids with closely related frequencies can be discriminated. A least-squares fit is then used to determine the coherent relative phase and amplitude of each tidal frequency within the total elevation, the remaining signal (the residual) is assumed to be non-tidal. Since this is a least-squares procedure gaps in the data are not a problem. We use the Titan harmonic tidal analysis package, developed and used by the Irish Sea Observatory (as part of the TASK 2000 software, http://www.pol.ac.uk/ntslf/software.html), to obtained the residual by harmonic tidal analysis. The software uses 24 major $\left(\mathrm{Q}_{1}, \mathrm{O}_{1}, \mathrm{M}_{1}, \mathrm{~K}_{1}, \mathrm{~J}_{1}, \mathrm{OO}_{1}, \mathrm{MU}_{2}, \mathrm{~N}_{2}, \mathrm{M}_{2}, \mathrm{~L}_{2}, \mathrm{~S}_{2}, 2 \mathrm{SM}_{2}, \mathrm{MO}_{3}, \mathrm{M}_{3}\right.$, 
$\left.\mathrm{MK}_{3}, \mathrm{MN}_{4}, \mathrm{M}_{4}, \mathrm{SN}_{4}, \mathrm{MS}_{4}, 2 \mathrm{MN}_{6}, \mathrm{M}_{6}, \mathrm{MSN}_{6}, 2 \mathrm{MS}_{6} 2 \mathrm{SM}_{6}\right)$ and 8 related $\left(\mathrm{PI}_{1}, \mathrm{P}_{1}, \mathrm{PSI}_{1}, \mathrm{PHI}_{1}\right.$, $2 \mathrm{~N}_{2}, \mathrm{NU}_{2}, \mathrm{~T}_{2}$ and $\mathrm{K}_{2}$ ) constituents in the analysis of a monthly record.

This method has the advantage that residuals are calculated at a high enough frequency to fully capture their time variations. The disadvantage is that whilst the tides are represented as discrete frequencies, in reality the energy peak is continuous over each band (diurnal, semi-diurnal, ...). This was described some time ago for the deep ocean - 'tidal cusps' (Munk et al., 1965; Cartwright and Amin, 1986). The problem is more acute in shelf seas where the sea's response to storms (changes in water level and in bed friction) can particularly affect the phase of the tide (for example Pugh and Vassie, 1976, Figure 5). This is manifested as a transitory signal with a semi-diurnal periodicity in the residuals. For storm surge studies this is overcome by considering skew surges (the difference between the maximum observed level and the predicted high water for each tidal cycle - hence only one value per tidal cycle, Horsburgh and Wilson, 2007). The problem seems to have generated more papers on how to calculate the tides accurately including the application of wavelets, rather than focussed on residuals (for instance Jay and Flinchem, 1999; Castenado et al., 2007; Leffler and Jay, 2009). One final point, since tidal variance dominates residual variance even a small error in tidal phase can have a large spurious impact on the residuals. Hence the only feasible method of calculating residuals is to perform a harmonic analysis on the observations, even if the data length is non ideal for tidal analysis, and not use an a priori estimate for the tide, as will be shown in Section 4. A caveat, particularly concerning short records is that the tidal analysis procedure may incorrectly partition the energy between tidal and non-tidal frequencies, over-estimating the tidal content and underestimating tide-surge interactions. There is a balance between ascribing too much energy at tidal frequencies to the tides and ascribing too little. 
The second method to estimating residuals is to use a low-pass filter. This overcomes the problems described above, for example Rossiter (1959), but has the disadvantage that high frequency information is lost. Additionally any gaps in the time series must be filled. A variety of low pass filters are possible (Hamming, 1983). The recursive Chebyshev Type II filter was chosen since the response in the pass-band is maximally flat and smooth and over the entire stopband the absolute difference between the ideal and actual frequency response is minimised, although there are ripples. The response function of the filter applied here has a stop-band for periods up to 26 hours and a pass-band for periods of 30 hours and longer, which enabled removal of all energy at tidal frequencies, including the diurnal tides. The pass-band ripple magnitude was set to a standard of 3 decibels and the stop-band attenuation was set to 30 decibels, which is an attenuation factor of 1000. This leaves only the long period residual without any tidal interaction, which will also have been removed by the filter since it is frequency dependant. This filtering process was applied in 2-way, so no phase shift occurs in the residual, however the start and end of the residual cannot be accurately obtained, hence a shorter time series is later presented.

\section{Validation of model results}

To enable model-observation comparison it is common practice (e.g. Prandle, 1975; Horsburgh and Wilson, 2007) to take the model residual (modelled total elevation minus modelled tidal elevation) and compare with the observed residual (observed total elevation minus predicted tide). However, long-term data (at least a year) is required for accurate harmonic tidal analysis to enable tidal prediction. Tidal interaction creating a non-tidal signal with frequencies matching tidal constituents is unlikely to continue in the long-term, e.g. any interaction with storm surges will be seasonal. In the short-term (a few months) a persistently strong interaction could influence the fit of the tidal components, and thus, important tidal modulation of the residual can 
be lost when removing the harmonically analysed tide. Alternatively, the (limited) number of constituents applied in the harmonic analysis may also cause non-removal of tidal constituents, leaving tidal energy within the observed residual signal. The limited number of model constituents may exclude some of those available in the harmonic analysis, leading to the removal of additional tidal energy from the modelled residual signal if used in the analysis.

Here, the reference model simulation is for POLCOMS-GOTM and considers the main processes: tide, surge, river flow, stratification, and their interactions. The predicted tide was generated using tidal harmonics obtained from tidal analysis of long-term (many years) observed total elevation from a tide gauge situated on the northern tip of Hilbre Island (Fig. 1). At the moorings the observed residual obtained using this predicted tide (blue line, Fig. 2) shows strong semi-diurnal oscillation, with maximum amplitude of about $10 \%$ of the tidal range (see later Fig. 5e), which decreases during strong wind events. This suggests that the tide within the estuary undergoes phase shifts due to shallow banks, and the presence of baroclinic and meteorological processes, causing the predicted tide at Hilbre Island to be slightly different to that at the mooring sites. Tidal analysis reveals an 11.5 minute and 16.2 minute shift in the tide occurs between Hilbre Island and the Hilbre channel and Welsh channel moorings respectively, which is sufficient to cause the modulation noticed in Figure 2. Using this predicted tide introduces artificial semi-diurnal (tidal) energy into the residual due to phase differences caused by the spatial variation. By using the modelled total and modelled tide alone elevations to extract the residual, no tidal energy is left within the residual. Any semi-diurnal oscillation can confidently be attributed to tide-residual interaction causing a phase shift in the modelled tide. For this study such oscillation is small compared with the size of the residual (see Fig. 2, green line). 
To enable a model-observation comparison harmonic tidal analysis was applied to the total elevation for the 25 day time series for both the model and the observation. The 25 day period allows the major tidal constituents to be removed, however any continuous interactions with constant phase over this period and with the same frequency as the tidal components are also removed and the analysis forces the mean water level to approximately zero. Ideally a long-term time series (many years) should be used so that the mean water level can be assumed to be zero. For a monthly harmonic tidal analysis the residual levels require a small shift to correct for seasonality in the mean level and other long-term cycles affecting the mean water level. The correction can be achieved by adding the mean of the modelled residual to the observed residual. Here the mean was corrected using the reference POLCOMS-GOTM simulation. At both locations the modelled (red line, Fig. 2) and observed (black line, Fig. 2) residuals obtained through harmonic tidal analysis are similar, and display similar pattern to that obtained by the difference in modelled total and tidal elevation (green line, Fig. 2), thus giving confidence in the modelling method, for the later process studies.

The residuals from the harmonic analysis display weak semi-diurnal variation (oscillation of the underlying pattern, black and red lines in Figure 2), which is greater than the variation obtained from the difference between modelled total and tidal elevation (green line, Fig. 2). This suggests tidal energy has been left in the harmonically analysed residual, which can be wrongly interpreted as tidal interaction, due to slight discrepancies between the harmonically analysed tide and the actual (observed/modelled) tide in the analysed data. Discrepancy is likely to occur due to tidal asymmetry forming within the estuary, generating higher harmonics. This oscillation is more noticeable during low surge $(<0.35 \mathrm{~m}$ elevation, Fig. 2$)$ conditions, when asymmetric tidal straining of the horizontal salinity gradient inducing a phase locked residual becomes more influential. During storm conditions (time 360 to 460 hours, Fig. 2) the harmonic analysis 
method predicts lower residual elevations, suggesting this method removes too much energy as a consequence of misrepresenting the tide, which is most likely to have undergone the greatest phase shift due to surge conditions. The underlying patterns are similar for the observed and modelled residuals extracted using the different techniques described. At both study locations the modelled and observed residual obtained through harmonic analysis have an $r^{2}$ value of 0.76 and an RMS error of $0.15 \mathrm{~m}$, suggesting the model accurately simulated the total residual component.
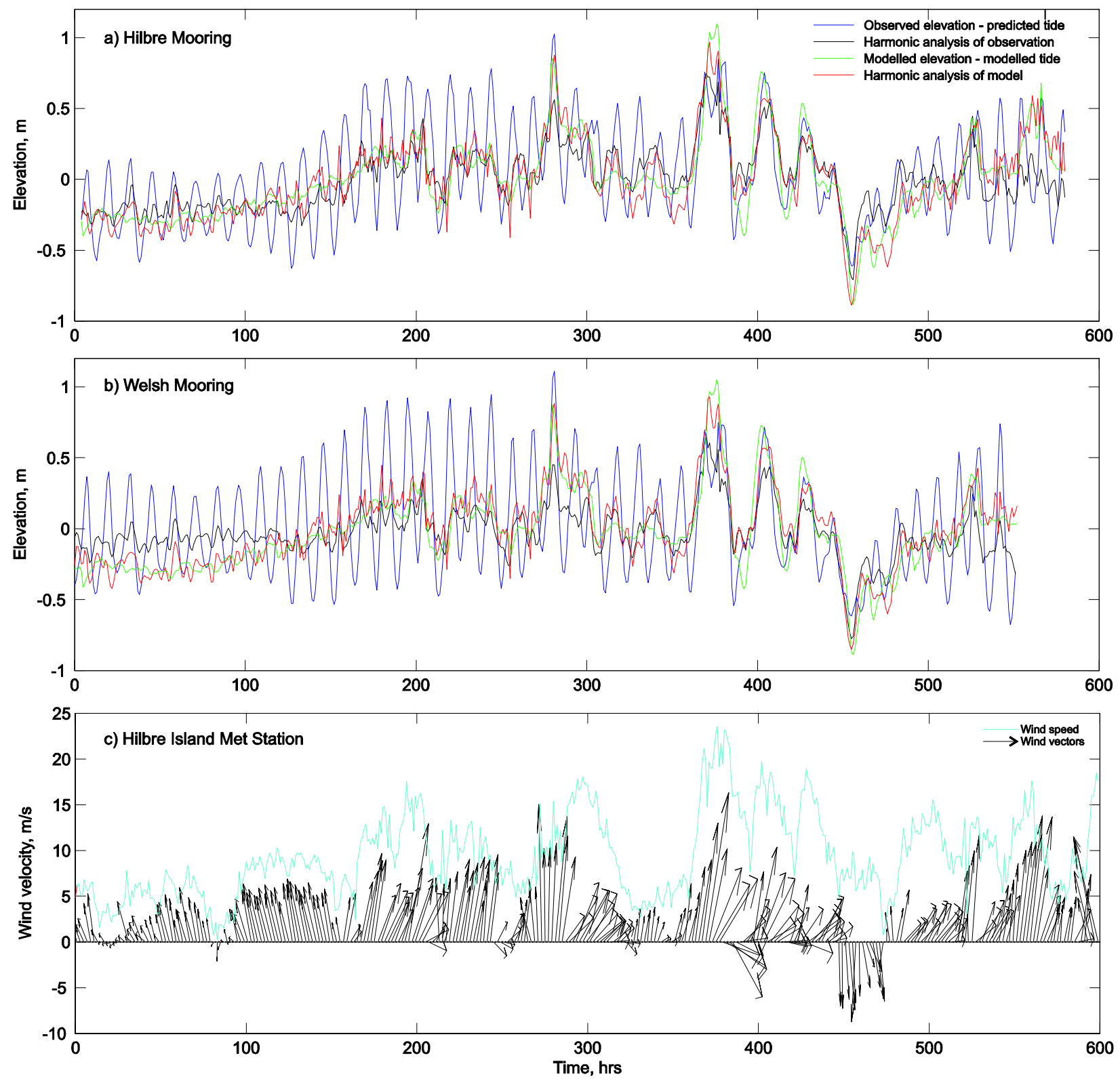
Fig. 2 The residual elevation obtained from the observed total elevation minus Hilbre predicted tidal elevation (blue line), the observed harmonic tidal analysis residual (black line), the modelled total elevation minus modelled tidal elevation (green line), the modelled harmonic tidal analysis residual (red line) at the Hilbre (a) and Welsh (b) mooring sites. The observed wind Cartesian convention at $10 \mathrm{~m}$ above the surface (c) is also given for the met station on Hilbre Island (located in Fig.1).

A filtering technique was also used to remove the tidal elevation, including any interaction, from the total elevation. By applying the same filter to both model and observed data enables a second method for model validation; again showing the model to have good agreement with observation (Fig. 3). The model has similar performance in both channels. The modelled and observed filtered residual has an $r^{2}$ value of 0.81 and 0.83 , in the Hilbre and Welsh channels and an RMS error of $0.12 \mathrm{~m}$ and $0.14 \mathrm{~m}$, respectively. The filtered (process induced) residual is noticeably smaller than the tidal range (see later Fig. 5e), even during storm events. Comparison of the observed filtered surge (solid black line, Fig. 3) with the observed harmonically analysed surge (red line, Fig. 3) shows the filtering technique removes all semi-diurnal variation, but still produces the same underlying pattern. Another effect of this filter may be to reduce the extreme values, seen by comparing the observed filtered and harmonically analysed residuals in Figure 3.

By using two consistent methods, either a filtering or harmonic tidal analysis technique, to compare the model with observation, the model has been confirmed to give good hindcast of the residual elevation at both locations. In the next section the model is used to investigate the contribution of each physical process during the 25 day period to the residual elevation. Both the process induced and process-interaction induced residual levels are used to determine their relative importance in generating the total residual level. 

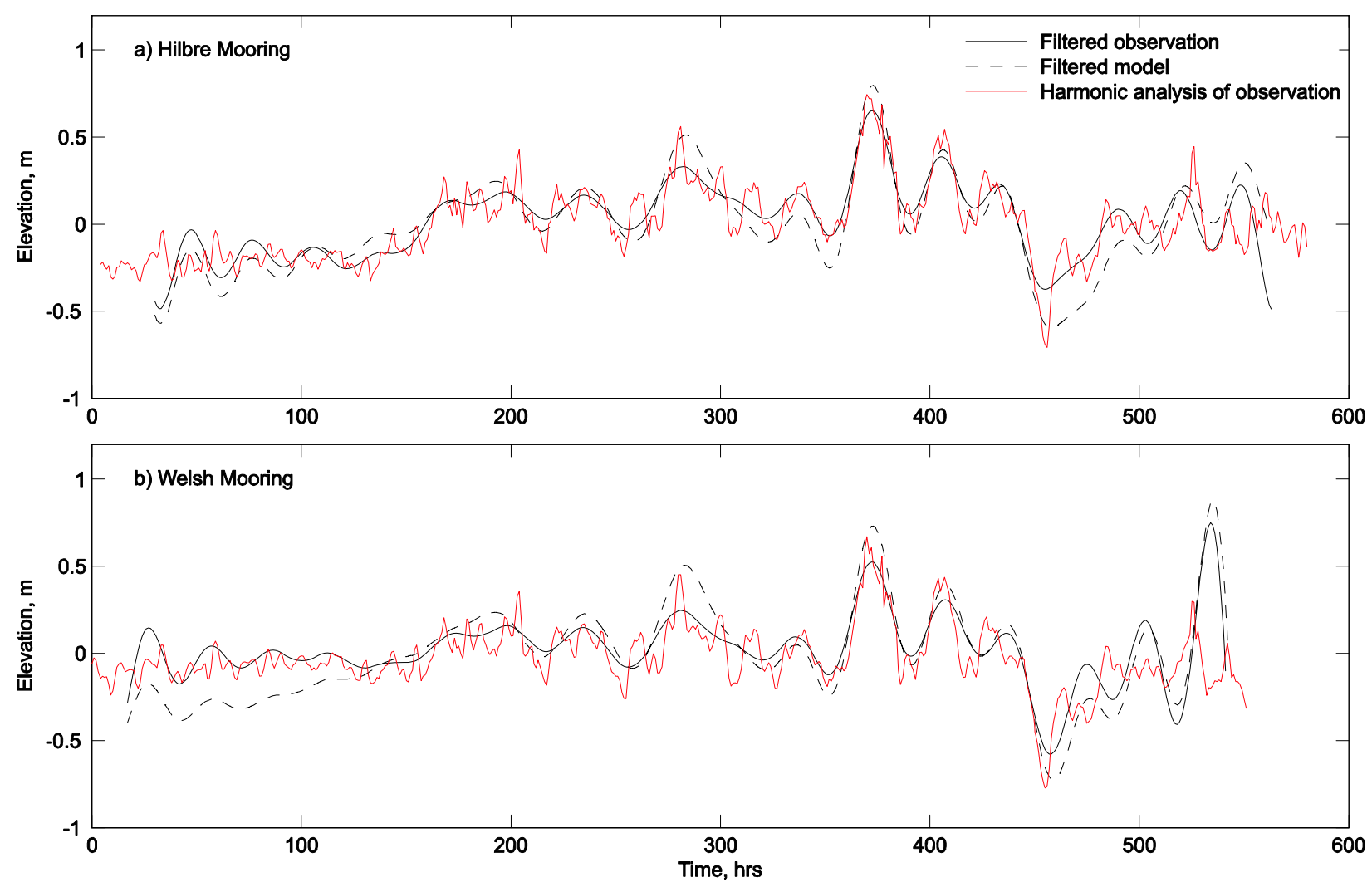

Fig. 3 The residual elevation obtained from the filtered observed (black line) and modelled (black dashed line) total elevations compared with the observed residual obtained through harmonic tidal analysis (red line) at the Hilbre (a) and Welsh (b) mooring sites.

\section{Process study results}

The validated model has been set up to perform a series of simulations to obtain residual elevations for a selection of processes, as described in Table 1, close to the estuary mouth. The processes are studied for the same period that observations were available in each channel. The difference between selected model runs is used to obtain the residual for the selected processes and their interactions (Fig. 4). Each residual has then been filtered using the filtering method described in Section 3 to obtain the process induced residual component without any interaction (Fig. 5a and b). The difference between the total residual and the filtered total residual provides the process-interaction induced component of that residual (Fig. 5c and d). 
To compare the residuals, metrics are given in Table 1. The mean of the filtered residual, although small $(<0.042 \mathrm{~m})$, indicates which process has most influence on the residual water level over the long-term. The maximum value of the filtered residual indicates which process has most short-term impact, i.e. during a specific event. Only the maximum of the processinteraction residual component is given to indicate which interactions have most influence on the residual in the short-term. Over the long-term the interactions have negligible effect (approximately zero mean). For this estuary river effect is mainly due to the induced stratification, the river flow having negligible effect in creating a residual at the mouth (Line $\mathrm{H}$, Fig. 4), so river flow effects are only briefly mentioned in following sections.

Table 1 The model runs considered a selection of the following processes: stratification (S), river flow (R), Metrological forcing (M), tides (T), waves (W) and external residual (E). Differences between the model simulations of selected processes (column 2) produced the studied residual elevations. A list of the processes included in each studied model residual (column 3) and the interactions between processes, denoted by '-' (column 4), affecting the residual are given. For the Hilbre (HC) and Welsh (WC) mooring the mean (column 5) and maximum (column 6) process induced (filtered) residual value for each simulation (Fig. 5 a and 
b), and the maximum (column 7) process-interaction residual component for each simulation

(Fig. $5 \mathrm{c}$ and d) are calculated for the full study period.

\begin{tabular}{|c|c|c|c|c|c|c|}
\hline $\begin{array}{l}\text { Residual } \\
\text { identity }\end{array}$ & $\begin{array}{l}\text { Model runs } \\
\text { subtracted to } \\
\text { obtain the } \\
\text { residual }\end{array}$ & $\begin{array}{l}\text { Processes } \\
\text { considered } \\
\text { in the } \\
\text { residual }\end{array}$ & $\begin{array}{c}\text { Interactions } \\
\text { between processes } \\
\text { considered }\end{array}$ & $\begin{array}{c}\text { Mean } \\
\text { process } \\
\text { induced } \\
\text { residual, m }\end{array}$ & $\begin{array}{l}\text { Max process } \\
\text { induced } \\
\text { residual, } \mathrm{m}\end{array}$ & $\begin{array}{c}\text { Max } \\
\text { interaction } \\
\text { induced } \\
\text { residual, m }\end{array}$ \\
\hline $\begin{array}{c}\mathrm{A} \\
\text { (reference case) }\end{array}$ & MSRT - PG_T & $\mathrm{M}, \mathrm{S}, \mathrm{R}, \mathrm{E}$ & $\begin{array}{c}\text { M-S, M-R, M-T, S- } \\
\text { R, S-T, R-T, E-T }\end{array}$ & $\begin{array}{c}\text { HC: } 0.0045 \\
\text { WC:-0.0211 }\end{array}$ & $\begin{array}{l}\text { HC: } 0.8022 \\
\text { WC: } 0.7583\end{array}$ & $\begin{array}{l}\text { HC: } 0.4888 \\
\text { WC: } 0.4771\end{array}$ \\
\hline B & MSRT - SRT & $\mathrm{M}$ & M-S, M-R, M-T & $\begin{array}{l}\text { HC:0.0144 } \\
\text { WC:0.0095 }\end{array}$ & $\begin{array}{l}\text { HC:0.1983 } \\
\text { WC:0.1652 }\end{array}$ & $\begin{array}{l}\text { HC:0.0854 } \\
\text { WC:0.0732 }\end{array}$ \\
\hline $\mathrm{C}$ & MSRT - MRT & $\mathrm{S}$ & M-S, S-R, S-T & $\begin{array}{l}\text { HC:0.0155 } \\
\text { WC:0.0112 }\end{array}$ & $\begin{array}{l}\text { HC:0.0200 } \\
\text { WC:0.0143 }\end{array}$ & $\begin{array}{l}\text { HC:0.0236 } \\
\text { WC:0.0196 }\end{array}$ \\
\hline $\mathrm{D}$ & MSRT - MT & $\mathrm{R}, \mathrm{S}$ & $\begin{array}{c}\text { M-S, M-R, S-R, S- } \\
\text { T, R-T, S-R, S-T, } \\
\text { R-T }\end{array}$ & $\begin{array}{l}\text { HC:0.0158 } \\
\text { WC:0.0114 }\end{array}$ & $\begin{array}{l}\text { HC:0.0203 } \\
\text { WC:0.0145 }\end{array}$ & $\begin{array}{l}\mathrm{HC}: 0.0254 \\
\mathrm{WC}: 0.0202\end{array}$ \\
\hline $\mathrm{E}$ & SRT $-\mathrm{T}$ & $\mathrm{R}, \mathrm{S}, \mathrm{E}$ & S-R, S-T, R-T, E-T & $\begin{array}{l}\text { HC:-0.0099 } \\
\text { WC:-0.0306 }\end{array}$ & $\begin{array}{l}\text { HC:0.6919 } \\
\text { WC:0.6834 }\end{array}$ & $\begin{array}{l}\text { HC:0.4126 } \\
\text { WC: } 0.4225\end{array}$ \\
\hline $\mathrm{F}$ & $\mathrm{MT}-\mathrm{T}$ & $\mathrm{M}, \mathrm{E}$ & M-T, E-T & $\begin{array}{l}\text { HC:-0.0113 } \\
\text { WC:-0.0325 }\end{array}$ & $\begin{array}{l}\text { HC:0.7834 } \\
\text { WC: } 0.7442\end{array}$ & $\begin{array}{l}\text { HC:0.4881 } \\
\text { WC: } 0.4762\end{array}$ \\
\hline G & MRT - T & $\mathrm{M}, \mathrm{R}, \mathrm{E}$ & $\begin{array}{c}\text { M-R, M-T, R-T, E- } \\
T\end{array}$ & $\begin{array}{l}\text { HC:-0.0109 } \\
\text { WC:-0.0323 }\end{array}$ & $\begin{array}{l}\text { HC:0.7838 } \\
\text { WC: } 0.7444\end{array}$ & $\begin{array}{l}\text { HC: } 0.4883 \\
\text { WC: } 0.4763\end{array}$ \\
\hline $\mathrm{H}$ & PMRT - MT & $\mathrm{R}$ & M-R, R-T & $\begin{array}{l}\text { HC:0.0003 } \\
\text { WC:0.0002 }\end{array}$ & $\begin{array}{l}\text { HC:0.0007 } \\
\text { WC:0.0006 }\end{array}$ & $\begin{array}{l}\mathrm{HC}: 0.0030 \\
\mathrm{WC}: 0.0023\end{array}$ \\
\hline I & $\begin{array}{c}\text { MRT - T - } \\
\text { MSRT + SRT }\end{array}$ & $\mathrm{R}, \mathrm{E}$ & R-T, M-S, E-T & $\begin{array}{l}\text { HC:-0.0254 } \\
\text { WC:-0.0418 }\end{array}$ & $\begin{array}{l}\text { HC:0.6735 } \\
\text { WC:0.6697 }\end{array}$ & $\begin{array}{l}\text { HC: } 0.4102 \\
\text { WC: } 0.4188\end{array}$ \\
\hline $\mathrm{J}$ & MSRTW -MSRT & $\mathrm{W}$ & $\begin{array}{c}\mathrm{M}-\mathrm{W}, \mathrm{S}-\mathrm{W}, \mathrm{R}-\mathrm{W} \\
\mathrm{T}-\mathrm{W}\end{array}$ & $\begin{array}{l}\text { HC:0.0002 } \\
\text { WC:0.0012 }\end{array}$ & $\begin{array}{l}\text { HC:0.0180 } \\
\text { WC:0.0222 }\end{array}$ & $\begin{array}{l}\text { HC:0.0192 } \\
\text { WC:0.0208 }\end{array}$ \\
\hline
\end{tabular}


The surge generated offshore from Liverpool Bay (Fig. 1) was considered as a boundary condition in all simulations apart from the tide only hindcast. The local surge generated within the model is expected to have a weak contribution to the total surge due to the small size of the (Liverpool Bay) model domain. For any residual that is generated using the tide only hindcast the external residual (to Liverpool Bay) is therefore not removed (residuals: A, E, F, G, I, Table 1). When the external residual is considered it dominates the residual magnitude (residuals A, E, F, G and I having similar values in Table 1), thus only run A is shown in later figures.

The external residual causes a negative mean residual over the study period. The locally generated residuals, without the external residual, produce weaker means over the study period (residuals B, C and D). Often the largest contribution to the residual elevation is caused by the process itself (column 6, Table 1) rather than its interaction (column 7, Table 1). Negligible residual (or interaction) is induced over the study period by river flow (residual $\mathrm{H}$ ) or waves (residual J); although during extreme river or wave events these residuals could have a stronger short-term influence. River flow is more likely to have greater influence further up-estuary and due to a weak flow during the study period it is not shown in the later figures, while wave events do have a weak impact at the mooring sites, which are close to the estuary mouth. The meteorological and stratification induced residuals, with (residuals E, F and G) and without (residuals B, C and D) external residual, have similar mean values and are most important. Apart from waves, both the mean and maximum process residual values are larger in the Hilbre than Welsh channel. The maximum process-interaction induced residual also follow this pattern. In the long-term, the residual water level is relatively small ( $<6 \mathrm{~cm}$ variation), but during events the level can vary significantly $(\leq 1 \mathrm{~m})$. 
The residuals studied (Table 1) comprise both the process and process-interaction induced components (Fig. 4). The residual therefore shows a pattern due to the process itself and semidiurnal oscillation due to its interaction with the tide. The combined residual for each process shows that in the Dee the external residual is the dominant process (Fig. 4 a and c), the secondary process is either local meteorology (residual B, Fig. 4 b and d), especially during storm events, or local stratification (residual C, Fig. 4 b and d), during calm periods. Local waves (residual H) followed by river flow (residual J) have the least impact (Fig. 4 b and d), the similarity in these residuals show the waves have slightly more impact than rives only during isolated events. The wave-induced surge is primarily due to wave setup generated by radiation stress. The wave enhancement of the surface and bottom roughness had little impact on the residual elevation compared with the model simulation without wave influence. The influence of the river flow on the other processes and the influence of other processes on the external residual are minimal. This is seen by the near identical nature of residuals $C$ and D in Figure $4 b$ and $4 d$, and the similarity between all residuals in Figure $4 \mathrm{a}$ and 4c. In the following figures only residuals with significant elevation are shown. 

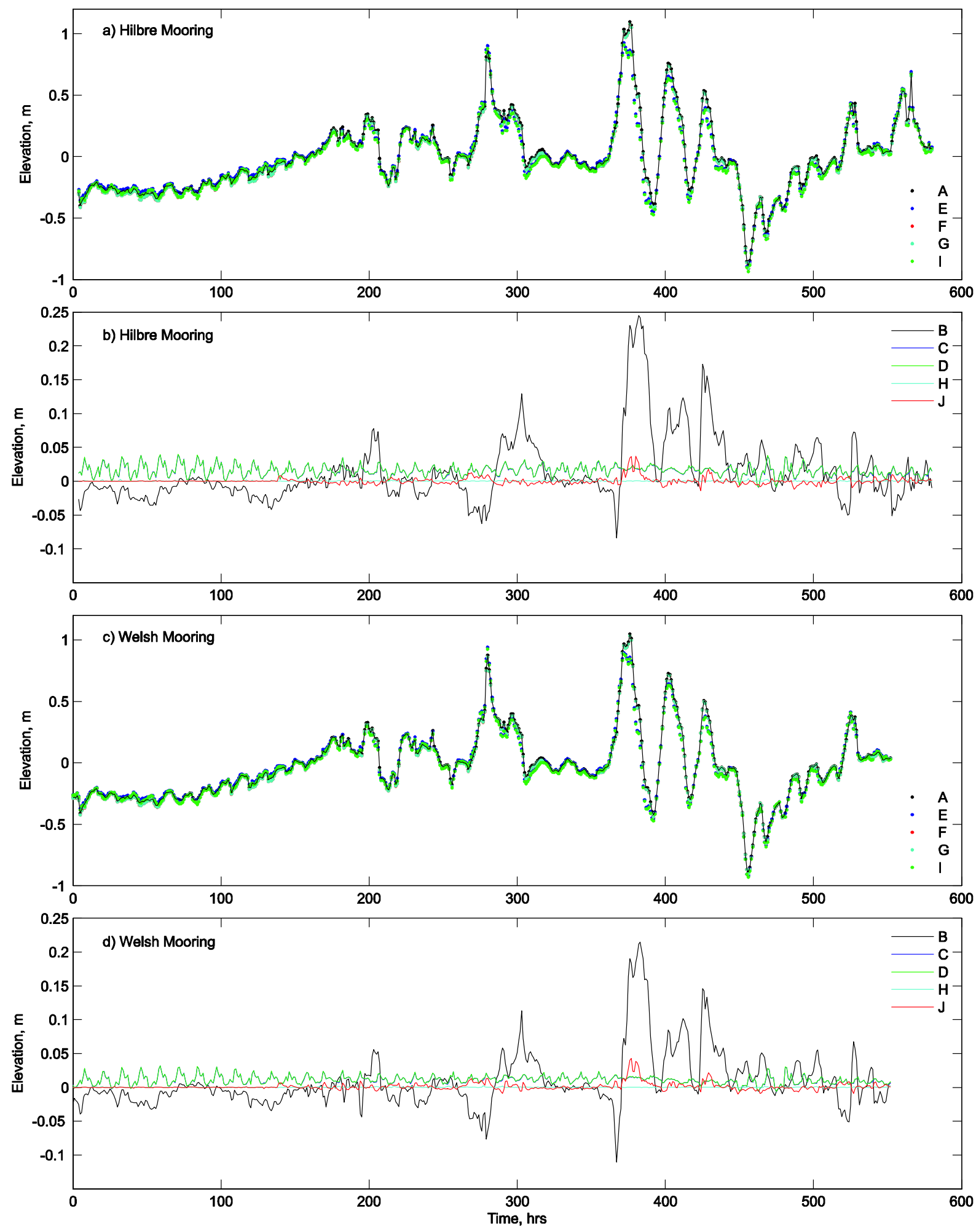

Fig. 4 The combined (total) modelled residual water elevations, due to a process and their interactions as given in Table 1, at the Hilbre ( $a$ and $b$ ) and Welsh (c and d) channel moorings. The residuals are separated into local combined with external processes (a and c) and local processes only ( $b$ and $d$ ) to enable scaling of the y-axis for clarity. 
The total residual for the isolated processes (Fig. 4) shows the considered processes to have the following order of importance in generating the overall residual elevation in the Hilbre (HC) and Welsh (WC) channels: the external $(109 \% \mathrm{HC}, 86 \% \mathrm{WC})$, then local meteorological (-12\% HC, $13 \% \mathrm{WC})$, then local stratification $(3 \% \mathrm{HC}, 0.4 \% \mathrm{WC})$, local waves $(2 \% \mathrm{HC}, 1 \% \mathrm{WC})$ and finally local rivers $(0.05 \% \mathrm{HC},-0.05 \% \mathrm{WC})$; where the percentage values are the mean values of the percentage each isolated processes and its interaction contribute to the overall residual, due to all processes and their interactions. Both the process induced (Fig. 5a and b) and the processinteraction induced (Fig. 5c and d) residual components, confirm this order of importance. The residual generated in the Hilbre channel (solid line, Fig. 5) lags that generated in the Welsh channel (crossed line, Fig. 5). This is most likely due to the Hilbre mooring being positioned further within the estuary and towards the east, allowing the tide-residual propagation to reach the Welsh mooring first, under the study conditions.

The external residual continually influences the water level having both a positive and negative contribution, with more extreme values during events, such as the passage of a low or high pressure system (residual A, Fig. 5a). The local meteorology has more noticeable effect during storm events (residual B, Fig. 5a), again acting to increase or decrease the water level depending on the wind direction and tidal flow direction in to the estuary at that time. Figure 5a shows the peaks in residual due to external and local processes may not coincide. During calmer conditions the influence of the local meteorology is still greater than the influence of stratification. Both the local meteorology and the external residual have a similar influence (in magnitude) on the two channels (crosses compared with solid lines, Fig. 5b). Stratification (residual C, Fig. 5b) is found to generally increase the water level by a few centimetres, having greater influence in the Hilbre channel (solid line C, Fig. 5) where the river has stronger impact. A period of northerly winds 
acting against the estuarine stratification profile does cause a reduction in the stratification induced residual ( $\sim 75 \mathrm{hrs,}$, residual C Fig. $5 b$ ). Waves (residual J, Fig. $5 b$ ) tend to increase the water levels when they are able to propagate into the estuary. Typically the waves have less influence than stratification and can cause a setup or set-down in water level during an event. Their influence is greater in the Welsh channel (crosses J, Fig. 5b) at the more exposed mooring location. During extreme events, the waves in the Welsh channel can have greater impact than stratification, increasing the water levels.

The interaction of the external residual with the tide as they propagate across the continental shelf leads to the largest process-induced residual (residual A, Fig. 5c), especially during storm events, a consequence of the residual causing a phase shift in the tide due to depth changes affecting its propagation speed. A generally diurnal signal is seen within this process-induced residual, which is weakest when winds are from the southeast. This oscillation is a response to the atmospheric forcing; the variability seen here often corresponds to a change in wind speed or direction. A weaker variability of roughly semi-diurnal frequency can also be seen under close inspection during the extreme storm event (time 360 to $460 \mathrm{hrs}$ ). This could be the response of the locally wind generated surge in shallow water to the tidal depth variation, or baroclinic processes, which also modify the tidal flow with semi-diurnal frequency, preventing a wholly elliptic or rectilinear pattern to form in Liverpool Bay (see Palmer, 2010).

The tide-external residual interaction has a larger signal for neap than spring tide conditions. This is seen by comparing the process residual peaks (residual A, Fig. 5a), tidal range (Fig. 5e) and range in the process-induced residual (residual A, Fig. 5c) at 285 hours with 410 hours, which are times of similar storm impact. This is most likely to be related to the storm conditions generating the external surge. The wind velocity is more southerly and weaker in the first 
instance and it is known strong south-westerly winds are associated with the largest surges in Liverpool Bay (Brown et al., 2010). This suggests it is the size of the surge and not the variability in tidal range that has more control on the amount of tide-surge interaction in an area. The surge induced depth change relative to the tidal range could be a factor influencing the interaction, but is less likely as the influence of depth on the surge propagation during different stages of the tide tends to cancel out. During storm conditions the surge elevates the water level, typically avoiding high water (Horsburgh and Wilson, 2007), thus could act to reduce the tidal range during that event. The local meteorology (residual B, Fig. 5c) has a moderate interaction during extreme storm events, the local wind having more influence through the water column at low water than high water.

Stratification (residual C, Fig. 5d) has a weak semi-diurnal interaction with the tide. The interaction is out of phase with the spring-neap cycle, with the largest interaction occurring during neaps when the tidal mixing is weaker. During extreme events, wind and wave mixing leads to the least interaction as the stratification is broken down. Wind straining can also act to increase/decrease the strength of the interaction. During southeast wind conditions the interaction with the tide is found to be weaker than that of stratification with the tide. During southwest to northerly wind conditions the opposite is true.

Local waves have the weakest tidal interaction within the residual, occurring only when they are able to propagate into the estuary (residual J, Fig. 5d); high water enabling them to propagate further than at low water due to banks at the mouth of the Dee. Their interaction is strongest during wave events and typically has semi-diurnal variability, with some higher frequency (hourly) variation in response to non-stationary wind conditions. This higher frequency variability is greater at the Hilbre mooring site, which experiences greater sheltering effect from 
the banks at the estuary mouth due to its position further within the Dee. Close to the estuary mouth during storm conditions, the local waves interact more strongly with the tide than the stratification (time 380 - 430 hours, Fig. 5d), and may also generate a larger contribution to the residual elevation during this time (time 380 hours, Fig. 5b). The stratification is found to have stronger interaction within the Hilbre channel than the Welsh channel, while the opposite is true for waves. This suggests river influence tends to favour the Hilbre channel while stronger mixing and wave influence occurs in the Welsh channel (as suggested by Bolaños et al., submitted). 

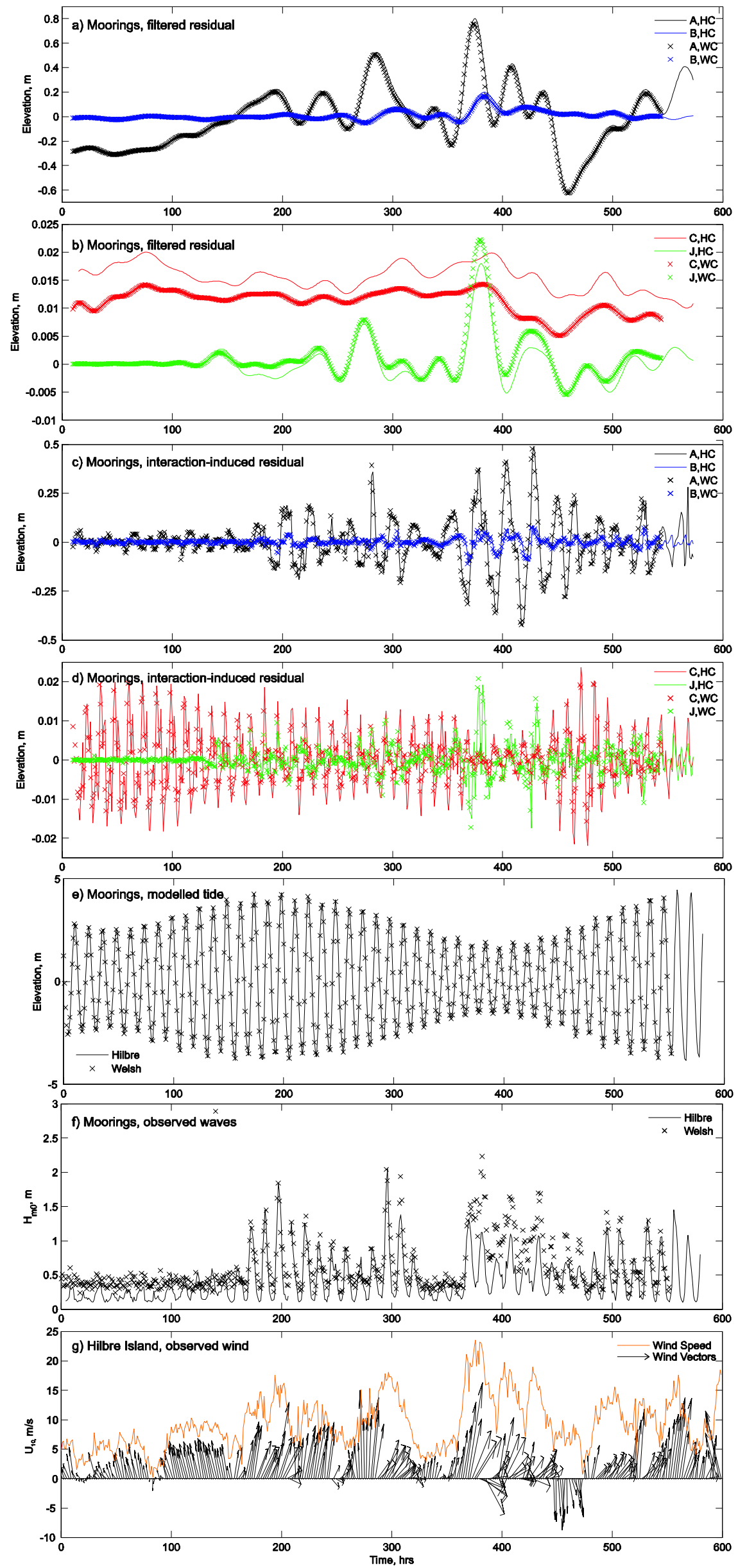
Fig. 5 The components that form the total residual: the process induced residual ( $a$ and $b$ ), obtained by filtering, and the residual caused by process interactions (c and d). The elevation axes vary in scale so the residuals can be clearly seen. The processes and interactions modelled are identified by letters A, B, C, and J and are defined in Table 1. The location Hilbre (HC) or Welsh (WC) channel is denoted by the second letter in the legend, the Hilbre channel being represented by the solid line and Welsh channel by the crosses. The modelled tide only elevation (e), observed wave heights (f) and observed wind (g) are also plotted.

\section{Discussion}

It has been shown (Section 4) that different residual water levels are obtained depending on the extraction techniques applied to the same data sets. This demonstrates the importance of using a consistent method for both observation and model output to enable validation. Using a valid model (Section 4) the contribution of different processes and their interactions to the total residual can be identified (Section 5). This shows the importance of using the correct model simulations to obtain the desired (total, process or process-interaction) residual for process studies.

Using the Dee Estuary, it is demonstrated that different local processes have variable impact within the channels of the same estuary. Consideration of the external residual greatly influences the total residual elevation. The impact of process-interaction can have a noticeable phase shift effect on the tide, generating a process-interaction induced residual. For management issues related to total water level, the total residual including the influence of the interacting processes should be included to obtain the total residual that occurs in addition to the predicted tide. Otherwise the change in water level could be incorrectly predicted. In this study, the maximum external processes induce a $0.8 \mathrm{~m}$ residual, when the external residual interaction with the tide 
causes a tidal phase shift increasing water levels by $0.2 \mathrm{~m}$, thus generating a total (process and interaction) external residual of $1.0 \mathrm{~m}$. At the time of high water the total increase in water level was $0.92 \mathrm{~m}$. This value is the skew surge, which would be used in flood risk analysis for this storm. In this study the local processes and process interactions are weak, with similar magnitude to the model (RMS) error. Unlike the external residual elevation they are therefore considered unimportant. However, comparison of the different processes within one modelling system enables improved understanding of how processes contribute and interact to form the total residual elevation. In other coastal and estuarine systems the local processes could be more important than that of the external residual.

Processes that continually modify the water level (external residual and stratification) continually interact with the tide, while event limited processes (local meteorology and waves) show stronger interaction at times when they are important. Any interaction causing a phase shift in the tide, which can be resolved by the sampling frequency of the data, will cause a semi-diurnal variation to remain in the residual when obtained from differences in the total (observed or modelled) and tidal (predicted or modelled) elevation or through harmonic analysis methods. It is suggested that modelling methods enable the full effect of this deviation to remain in the residual, while harmonic tidal analysis (partly) modify and filtering methods (fully) remove this component of the residual. This is clearly demonstrated, in Figure 2 and 3, by the variation in the smoothness of the time-varying residual elevation when obtained by different techniques. When extracting the residual (from observation or model simulation) it is therefore important to be aware of what the chosen method will remove to produce the residual, in case important process interactions or the processes themselves are lost. Filtering methods will always extract the residual due to the process itself, removing all tidal energy and interaction, providing a robust method for model validation or study of a process-induced residual without the influence of local 
process-interaction. An alternative method, where the diurnal astronomic tidal amplitudes are small, as here, to avoid removal of any residual component at the diurnal frequencies, is to apply a harmonic tidal analysis (to model or observational data) and filter the resultant residual, to remove energy from semi-diurnal frequencies and higher. By filtering after tidal analysis has been applied allows the filter design to be specific, for example, the long period (diurnal) tidal signal will be removed so a lower rejection threshold (a stop-band of 20 hours) can be applied in the filter to target energy of shorter period (semi-diurnal) tidal signal. Although harmonic tidal analysis of short-term data $(<1 \mathrm{yr})$ provides a method for model validation it does not allow study of the observed residual with full process-interaction, due to partial modification of the semi-diurnal modulation within the residual. Thus, for short-term study ( $\sim 1$ month), modelling techniques are considered the most robust way to ensure all processes and their interactions are captured. For long-term data ( $>1 \mathrm{yr})$ more tidal constituents can be resolved using harmonic tidal analysis and a more accurate residual is obtained. Coastal management requires the best knowledge of the total water level, the residual required is therefore the water elevation in addition to the predicted tide. In the absence of long-term observation a baroclinic model is required in regions of freshwater (estuaries) to capture the tidal distortion, since stratification does contribute to residuals, even for macrotidal estuaries with weak river flow.

All local physical processes modelled show a weak semi-diurnal variation in response to the large range in tidal elevation and currents in this study area. For microtidal location the interactions will be weaker and harmonic analysis is likely to be more accurate at residual extraction. In the macrotidal Dee Estuary the strongest interaction with the tide occurs with the external residual during storm events (residual A, Fig. 5c). The locally generated residuals (residuals B, C and J, Fig. $5 \mathrm{c}$ and d) show weaker tidal interaction due to the shorter (local) fetch across which they interact. Locally the wind has the primary influence on the residual water 
level; during calm conditions stratification-induced water levels become important, and can have greater influence than the wind when the combined process induced and process-interaction induced residuals are considered. Wave-induced water levels are least important, but may become more important than stratification, during an extreme wave event close to the estuary mouth. Depending on wind and wave direction, and the tidal level, a set down or setup in the water level may occur. During this study the mean process induced residual is close to zero (Table 1), with a predominant setup in the Hilbre channel and set down in the Welsh channel. Variation in water level generated externally to the estuary, usually by meteorology, is the major component influencing the estuarine water elevation close to the mouth. During the studied storm event the total maximum residual is about $1.1 \mathrm{~m}$ (i.e. the maximum increase of the predicted tidal elevation, which is unlikely to occur at high water), although the local processes only contribute about $0.7 \mathrm{~m}$ to the water level at this time. Due to the nonlinear interactions distorting the tide, the local and external process induced water levels cannot simply be added together to provide the total residual elevation, the effect of interactions must also be considered. In this study the local and external (storm) peaks in the process residuals are also out of phase, due to different generation and propagation processes.

\section{Conclusion}

Using observations in the Dee Estuary, northwest England, a modelling system to investigate the components of the residual elevation within a macrotidal estuary has been set up and validated. It has been shown that process-interactions external and local to the estuary system distort the tide making extraction of the residual difficult. The process-interactions can be partly removed using harmonic tidal analysis and are fully removed using filtering techniques. The differences in the residual obtained through: harmonic analysis methods, filtering methods and modelling techniques, illustrates how important it is to consider what components are required to be kept 
within the residual and whether consistent methods have been used to enable model validation. By using a valid model the total elevation residual including tidal distortion due to (baroclinic and external surge) interaction can be obtained. Such a modelling system also enables determination of isolated contribution of physical processes to the residual and the strength of the interaction between these processes and the tide. Further work will be to investigate how wetting and drying of the intertidal influences the residuals and their tidal interaction, through the modification of the estuarine volume, e.g., estuarine fetches are determined by bank exposure and water becomes constrained in channels during low water levels.

Near to the estuary mouth, for this macrotidal estuary with weak river flow, it is shown that the residual elevation generated externally to the estuary has most influence, while the local meteorology and stratification have a secondary influence. Although the study locations were close to the mouth, the restriction of wave activity due to the shoals of banks means that waves have little impact generating residual elevations even during storm events. The model results suggest the tide plays an important role interacting with the local, and even more so, with the external residuals, leading to semi-diurnal and diurnal variation of the residual components. The results may be different further up estuary as higher tidal harmonics and river influence become more important. For management requiring knowledge of extreme conditions, the correct residual extraction must be used, so the actual total water level can be determined. It is suggested using the difference between total and tidal elevations, whether modelled or from long-term observation, is the best approach to use, since this residual consists of the process induced and process interaction induced components and represents the residual elevation in addition to the tide. In the absence of long-term (at least a year) observation to generate a predicted tide a validated model is preferable for short-term studies. Using modelling methods also prevents errors occurring in the tidal fit through the choice of constituents and the 
occurrence of tidal asymmetry. The techniques presented will enable further studies to assess the contribution of different processes to the residual current, which will be of importance for understanding sediment movement and morphological evolution of an estuarine system.

\section{Acknowledgments}

This research has been carried out as part of Oceans 2025, the FORMOST project (NERC grant NE/E015026/1) and the Field_AC project (EC grant 24284). Jane Williams (NOC) is thanked for providing the operational surge model output and meteorological (wind and pressure) data, while Clare O'Neill is thanked for providing the offshore temperature and salinity fields to the Irish Sea and supplementing the meteorological forcing with air temperature, humidity, and cloud cover to enable full atmospheric forcing.

\section{References}

Amin M (1982) On analysis and forecasting of surges on the west coast of Great Britain.

Geophysical Journal of the Royal Astronomic Society, 68(1): 79-94.

Bolaños R, Souza A (2010) Measured hydrodynamics and sediment transport processes in the Dee Estuary. Earth Systems Science Data 2:157-165.

Bolaños R, Brown JM, Souza A (2011) Three dimensional circulation modeling in the Dee Estuary. Journal of Coastal Research SI (64): 1457-1461.

Bolaños R, Brown JM, Amoudry LO, Souza A (Submitted). Tides, river and wind influence on the circulation in a macrotidal estuary. Submitted to Journal of Physical Oceanography.

Brown JM, Souza AJ, Wolf J (2010) An 11-year validation of wave-surge modelling in the Irish Sea, using a nested POLCOMS-WAM modelling system. Ocean Modelling 33(1-2): $118-128$. 
Cartwright DE, Amin M (1986) The variances of tidal Harmonics. Deutsche Hydrographische Zeitschrift, 39(6): 235-253.

Castanado S, Mendez FJ, Medina R, Abascal AJ (2007) Long-term tidal level distribution using a wave-by-wave approach. Advances in water resources, 30(11): 2271-2282.

De Vries H, Breton M, De Mulder T, Krestenitis Y, Ozer J, Proctor R, Ruddick K, Salomon JC, Voorrips A (1995) A comparison of 2D storm surge models applied to three shallow European seas. Environmental Software 10(1): 23-42.

Emery WJ, Thomson RE (2001) Data analysis methods in physical oceanography. $2^{\text {nd }}$ edition, Elsevier Science, Amsterdam, pp 638.

Godin G, (1972) The analysis of Tides, Liverpool University Press, 264pp.

Goring DG, Stephens SA, Bell RG, Rearson CP (2011) Estimation of extreme sea levels in a tide-dominated environment using short data records. Journal of Waterway, Port, Coastal, and Ocean Engineering 137(3): 150-159.

Hamming RW (1983) Digital Filters. $2^{\text {nd }}$ edition, Englewood Cliffs, New Jersey, Prentice-Hall, $257 \mathrm{pp}$.

Holt JT, James ID (2001) An s coordinate density evolving model of the northwest European continental shelf: 1, model description and density structure. Journal of Geophysical Research 106 (C7):14,015-14,034.

Horsburgh K J, Wilson C (2007) Tide-surge interaction and its role in the distribution of surge residuals in the North Sea, Journal of Geophysical Research 112(C08003), 13pp, doi:10.1029/2006JC004033.

Jay DA, Flinchem EP (1999) A comparison of methods for analysis of tidal records containing multi-scale non-tidal background energy. Continental Shelf Research, 19(13): 16951732. 
Jevrejeva S, Moore JC, Grinsted A, Woodworth PL (2008) Recent global sea level acceleration started over 200 years ago? Geophysical Research Letters 35(L08715), 4pp.

Komen GJ, Cavaleri L, Donelan M, Hasselmann K, Hasselmann S, Janssen PAEM (1994) Dynamics and modelling of ocean waves. Cambridge University Press, Cambridge, $532 \mathrm{pp}$.

Leffler KE, Jay DA (2009) Enhancing tidal harmonic analysis: Robust (hybrid $\mathrm{L}^{1} / \mathrm{L}^{2}$ ) solutions. Continental Shelf Research, 29(1): 78-88.

Mastenbroek C, Burgers G, Janssen PAEM (1993) The dynamical coupling of a wave model and a storm surge model through the atmospheric boundary layer. Journal of Physical Oceanography 23(8): 1856-1866.

Monbaliu J, Padilla-Hernández R, Hargreaves JC, Carretero-Albiach JC, Luo W, Sclavo M, Günther H (2000) The spectral wave model WAM adapted for applications with high spatial resolution. Coastal Engineering 41(1-3): 41-62.

Munk WH, Zetler B, Groves GW (1965) Tidal cusps. Geophysical Journal of the Royal Astronomic Society, 10(2): 211-219.

Palmer MR (2010) The modification of current ellipses by stratification in Liverpool Bay ROFI. Ocean Dynamics 60(2): 219-226.

Prandle D (1975) Storm surges in the southern North Sea and River Themes, Proceedings of the Royal Society London A 344(1639): 509-539.

Pugh DT (1987) Tides, surges and mean sea level. J. Wiley, Chichester, 472pp.

Pugh DT, Vassie JM (1976) Tide and surge propagation off-shore in the Dowsing region of the North Sea. Deutsche Hydrographische Zeitschrift, 29(5): 163-213.

Pye K (1996) Evolution of the shoreline of the Dee Estuary, United Kingdom. In: KF Nordstrom, CT Roman (Eds.) Estuarine Shores: Evolution, Environments and Human Alterations. John Wiley \& Sons Ltd, p14-37. 
Rossiter JR (1959) A method for extracting storm surges from tidal records. Deutsche Hydrographische Zeitschrift, 12(3): 117-127.

Umlauf L, Burchard H (2005). Second-order turbulence closure models for geophysical boundary layers. A review of recent work. Continental Shelf Research 25(7-8): 795827. 